\title{
A 32-year Perspective on the Origin of Wind Energy in a warming Climate
}

\section{Citation}

Huang, Junling, and Michael B McElroy. 2015. A 32-year perspective on the origin of wind energy in a warming climate, Renewable Energy 77, no. May: 482-492.

\section{Published Version}

http://www.sciencedirect.com/science/article/pii/S0960148114008726

\section{Permanent link}

http://nrs.harvard.edu/urn-3:HUL.InstRepos:13919173

\section{Terms of Use}

This article was downloaded from Harvard University's DASH repository, and is made available under the terms and conditions applicable to Other Posted Material, as set forth at http:// nrs.harvard.edu/urn-3:HUL.InstRepos:dash.current.terms-of-use\#LAA

\section{Share Your Story}

The Harvard community has made this article openly available.

Please share how this access benefits you. Submit a story.

Accessibility 
1 A 32-year Perspective on the Origin of Wind Energy in a warming Climate

2 Junling Huang ${ }^{\text {a } b^{*}}$, Michael B. McEIroy ${ }^{\text {a }}$

$3 \quad{ }^{a}$ School of Engineering and Applied Sciences, Harvard University, Cambridge, MA 02138, USA

$4 \quad$ b John F. Kennedy School of Government, Harvard University, Cambridge, MA 02138, USA

$5 *$ Corresponding author

$6 \quad$ Tel.: 617-955-6282

$7 \quad$ Email: junling_huang@post.harvard.edu

8

9

10

11

12

13

14

15

16

17

18

19 


\section{Abstract}

21 Based on assimilated meteorological data for the period January 1979 to December 2010, the 22 origin of wind energy is investigated from both mechanical and thermodynamic perspectives, 23 with special focus on the spatial distribution of sources, historical long term variations and the

24 efficiency for kinetic energy production. The dry air component of the atmosphere acts as a 25 thermal engine, absorbing heat at higher temperatures, approximately $256 K$, releasing heat at 26 lower temperatures, approximately $252 \mathrm{~K}$. The process is responsible for production of wind 27 kinetic energy at a rate of $2.46 \mathrm{~W} / \mathrm{m}^{2}$ sustaining thus the circulation of the atmosphere against 28 frictional dissipation. The results indicate an upward trend in kinetic energy production over the 29 past 32 years, indicating that wind energy resources may be varying in the current warming 30 climate. This analysis provides an analytical framework that can be adopted for future studies 31 addressing the ultimate wind energy potential and the possible perturbations to the atmospheric 32 circulation that could arise as a result of significant exploitation of wind energy.

34 Keywords: origin of wind energy; warming climate; thermal engine; interannual variability 


\section{Introduction}

44 Global installed wind capacity reached an unprecedented level of more than $318 G W$ at the end

45 of 2013, of which approximately $35 \mathrm{GW}$ were added in 2013 , the highest level recorded to date.

46 Wind power contributes close to $4 \%$ to current total global electricity demand. In total, 103

47 countries are using wind power on a commercial basis. Based on current growth rates, the World

48 Wind Energy Association estimates that global wind capacity could increase to as much as

$49700 G W$ by $2020[1]$.

50 A number of studies have sought to assess the ultimate potential for wind-generated electricity

51 assuming that the deployment of turbines should not influence the potential source [2-8]. Using

52 data from surface meteorological stations, Archer and Jacobson [4] concluded that $20 \%$ of the

53 global total wind power potential could account annually for as much as $123 \mathrm{PWh}$ of electricity,

54 equivalent to 7 times total current global consumption. They restricted their attention to power

55 that could be generated using a network of $1.5 \mathrm{MW}$ turbines tapping wind resources from

56 regions with annually averaged wind speeds in excess of $6.9 \mathrm{~m} / \mathrm{s}$ at an elevation of $80 \mathrm{~m}$. Using

57 assimilated meteorological data, Lu et al. [5] argued that a network of land-based $2.5 \mathrm{MW}$

58 turbines restricted to non-forested, ice-free, non-urban areas operating at as little as $20 \%$ of their

59 rated capacity could supply more than 40 times current worldwide demand for electricity, more

60 than 5 times total global use of energy in all forms.

61 Numerous groups have argued that large scale deployment of wind farms could potentially

62 influence the circulation of the atmosphere, altering consequently the global wind energy

63 resources [9-16]. For example, Adams and Keith [16] tried to quantify the limitation of wind

64 energy extraction using a mesoscale model and compared their results with other studies using 

77 been quantified.

global atmospheric models. The energetics of the entire atmosphere is different from the energetics of the mesoscale region considered by Adams and Keith [16]. It is essential to understand how kinetic energy of wind is created in the entire atmosphere.

Wind energy is essentially the kinetic energy held by the center-of-mass movement of a volume element of air. The movement of the air is driven primarily by the spatial gradient in heat input. Diabatic heating occurs mainly in the warm tropics, with diabatic cooling dominating at relatively cold mid and high latitudes. In this sense, following Carnot, the dry air component of the atmosphere acts as a thermal engine, converting heat to kinetic energy to sustain the general circulation against the force of friction. The standard approach to investigate the energetics of the atmosphere was introduced by Lorenz in 1955 [17]. A number of groups have analyzed the energetics of the atmosphere based on the Lorenz Energy Cycle [18-22]. However, the geographic distribution of kinetic energy production and the temporal variability have not as yet

This study investigates the origin of wind energy, with a specific focus on the spatial distribution of sources, historical long term variations and the efficiency for kinetic energy production. From a mechanical perspective, kinetic energy can be produced or destroyed only by real forces [23]. In the case of an air parcel in the atmosphere, the real forces are: gravity, the pressure gradient force, and friction. From a thermodynamic perspective, the creation of wind energy in the atmosphere involves absorption of heat at high temperature and release at low temperature, following the operational principle of a thermal engine. The paper also analyzes the thermodynamic processes within the atmosphere, quantifying the key thermodynamic variables including the net rate of heat absorption and the efficiency for kinetic energy production. The analysis provides a historical perspective on the production of kinetic energy in the atmosphere 
and an analytical framework for future studies exploring the ultimate potential for wind energy and potential for significant change in the circulation of the atmosphere as a consequence of future large scale turbine deployment.

\section{MATERIALS}

The study is based on meteorological data from the MERRA compilation covering the period January 1979 to December 2010. Kinetic energy of wind, wind speeds, air temperatures, geopotential heights and surface roughness were obtained on the basis of retrospective analysis of global meteorological data using Version 5.2.0 of the GEOS-5 DAS. We use the standard 3hourly outputs of the free atmosphere conditions and the standard hourly outputs of the boundary layer conditions [24]. The multivariate ENSO index is from the National Oceanic and Atmospheric Administration (available at: http://www.esrl.noaa.gov/psd/enso/mei/).

\section{Atmospheric kinetic energy}

The kinetic energy corresponding to unit mass of the atmosphere is given by $|\vec{v}|^{2} / 2$ where $\vec{v}$ is the wind speed. The total and hemispheric atmospheric kinetic energy stocks may be obtained by integrating over the appropriate spatial domains. Composite results for monthly mean values and for the long-term variation of global kinetic energy are shown in Fig. 1. The inter-annual variation of the total kinetic energy stock is associated with the changing phases of the El Niño Southern Oscillation (ENSO) cycle (Fig. 1a and Fig. 2). During the warm El Nino phase (notably years 1983, 1987, 1997 and 2010), elevated sea surface temperatures (SSTs) result in an increase in the kinetic energy stock; during the cold phase La Nina phase (notably years 1985, 1989, 1999 and 2008), colder SSTs contribute to a decrease. The global kinetic energy stock averaged approximately $1.50 \mathrm{MJ} / \mathrm{m}^{2}$ over the past 32 years, $1.31 \mathrm{MJ} / \mathrm{m}^{2}$ in the Northern Hemisphere with $1.70 \mathrm{MJ} / \mathrm{m}^{2}$ in the Southern Hemisphere. 
111 The spatial distributions of the annual mean, June - August, and December - February kinetic energy

112 budgets are shown in Fig. 3. Clearly evident is the influence of the dominant storm tracks at mid-

113 latitude, and the steady components of the subtropical and polar jet streams. There are two

114 distinct peaks in the Northern Hemispheric kinetic energy stock east of Japan and east of the

115 North American continent, with a more continuous belt of high kinetic energy located between

$11630{ }^{\circ} \mathrm{S}$ and $60{ }^{\circ} \mathrm{S}$ in the Southern Hemisphere. As discussed by Huang et al. [25], the boundary

117 layer wind, for example the wind at $100 \mathrm{~m}$, is controlled by conditions in the free atmosphere,

118 perturbed by fast varying turbulence in the boundary layer. Strong winds in the free atmosphere

119 generally lead to strong winds near the surface, and consequently to high instantaneous values of

120 the capacity factors for wind turbines. The spatial distributions in Fig. 3 reflect the geographic

121 distribution and seasonality of wind resources as reported in the earlier studies [5, 26, 27].

\section{4. Production of kinetic energy}

123 For an air parcel of unit mass, production of kinetic energy may be written as:

124

$$
\frac{d K}{d t}=-g w-\frac{1}{\rho} \vec{v} \cdot \nabla p+\vec{v} \cdot \vec{F}
$$

125 where $K$ is the kinetic energy corresponding to unit mass, $g$ is the gravitational acceleration, $w$ is

126 the vertical velocity, $\vec{v}$ is the velocity, $\rho$ is the air density, $p$ is the pressure and $\vec{F}$ is the frictional

127 force.

In calculating the kinetic energy production rate, it is convenient to consider the rate for

129 production of kinetic energy in a fixed unit of volume. Re-organizing equation (1), we have:

$$
\frac{\partial \rho K}{\partial t}=-\nabla \cdot(K \rho \vec{v})-\vec{v} \cdot \nabla p+\rho \vec{v} \cdot \vec{F}-g \rho w
$$

131 The left hand side of this equation denotes the rate per unit volume for production of kinetic 
132 energy. The right hand side defines contributions to the production rate associated with the

133 convergence of the kinetic energy flux $(-\nabla \cdot(K \rho \vec{v}))$, and the work carried out or consumed by

134 the pressure gradient force $(-\vec{v} \cdot \nabla p)$, friction $(\rho \vec{v} \cdot \vec{F})$ and gravity $(-g \rho w)$.

135 The atmosphere is in quasi-hydrostatic balance: gravity is balanced approximately by the vertical

136 pressure gradient force. In this case, equation (2) may be recast in the simpler form:

$$
\frac{\partial \rho K}{\partial t}=-\nabla \cdot(K \rho \vec{v})-\overrightarrow{v_{h}} \cdot \nabla_{h} p+\rho \vec{v} \cdot \vec{F}
$$

138 where $\overrightarrow{v_{h}}$ is the horizontal component of $\vec{v}$, and $\nabla_{h} p$ is the horizontal gradient of the pressure 139 force. Production of kinetic energy in the atmosphere, $C$, can be estimated as $C=-v_{h} \cdot \nabla_{h} p[17$ 140 22].

141 Fig. 4 illustrates the distribution of kinetic energy production, $C$, averaged over the past 32 years 142 in units of $10^{-3} \mathrm{~W} / \mathrm{kg}$. The tropical and subtropical region from $30^{\circ} \mathrm{S}$ to $30^{\circ} \mathrm{N}$, dominated by 143 the thermally direct Hadley circulation, is responsible for a net source of kinetic energy as 144 indicated in Fig. 4a. The most prominent sources are located in the mid-latitude oceanic regions 145 below the $800 \mathrm{hPa}$ pressure level, notably in the Southern Hemisphere, as depicted in Fig. 4c. 146 Production of kinetic energy in these regions is associated with the intense development of 147 eddies that stir the atmosphere over the ocean, carrying cold air equatorward and warm air 148 poleward, resulting consequently in cross-isobaric flow. The topographic forcing of the Tibetan 149 plateau has a noticeable impact on the production of kinetic energy in the upper region of the 150 atmosphere, from $0 \mathrm{hPa} \sim 600 \mathrm{hPa}$, as indicated in Fig. $4 \mathrm{~b}$.

151 The global and hemispheric rates for production of kinetic energy are obtained by integrating the 152 production term, $C$, over the entire atmosphere or over each hemisphere separately. The global 153 kinetic energy production rate averaged over the past 3 decades is estimated at $2.46 \mathrm{~W} / \mathrm{m}^{2}$, with 
154 a upward trend since the late 1990s (Fig. 5a). The average rate for production in the Northern

155 Hemisphere is $2.44 \mathrm{~W} / \mathrm{m}^{2}, 2.49 \mathrm{~W} / \mathrm{m}^{2}$ for the Southern Hemisphere. Hemispheric production

156 rates indicate strong seasonality (Fig. 5c), reaching maximum power output during local winter,

157 with minima in local summer.

158

159

160

161

162

163

164

165

166

167

168

169

170

171

172 173 The fate of kinetic energy in the atmosphere from a mechanical perspective is summarized in Fig. 174 7. The residence time of kinetic energy, $\tau$, calculated as $K E / D$, is 6.9 days.

\section{Dissipation}

Motions of the atmosphere against friction convert kinetic to internal energy. This process is thermally irreversible, resulting in an increase in entropy. Approximately half of the frictional dissipation takes place within the lowest kilometer of the atmosphere, a result of turbulent motions generated mechanically by the flow over the underlying surface. The other half takes place higher in the atmosphere where small-scale disturbances are generated as a result of convection or shear instability of the vertical wind [28]. In the long run, the total kinetic energy in the atmosphere, $K E$, is determined by a balance between production, $C$, and dissipation by friction, $D$. The dissipation term may be quantified according to:

$$
D=C-\frac{d K E}{d t}
$$

The long-term variation and seasonal cycle of $D$ are plotted in Fig. 6. Maximum dissipation occurs in February, corresponding to the peak in Northern Hemisphere kinetic energy reflecting the importance of surface roughness associated with Northern Hemisphere continental areas in dissipating kinetic energy. The entropy generation associated with dissipation can be approximated as $\frac{C}{T_{\text {surface }}}$, where $T_{\text {surface }}$ is the global average surface atmosphere (about $280 \mathrm{~K}$ ).

\section{The thermodynamics of atmospheric motions}


According to the first law of thermodynamics:

$$
C_{p}\left[\frac{\partial}{\partial t} T+\vec{v} \cdot \nabla T+\omega\left(\frac{\partial T}{\partial p}-\kappa \frac{T}{P}\right)\right]=Q
$$

where $Q$ defines the rate per unit mass of dry air for diabatic heating, $C_{P}$ is the specific heat of the air, $T$ is temperature, $\omega$ is the vertical component of wind velocity in an isobaric system and $\kappa=0.286$ [29].

The annual mean spatial distribution of diabatic heating $Q$ based on equation (5) is displayed in Fig. 8. The results presented here are consistent with earlier studies [30, 31]. An important fraction of the incoming sunlight reaches the surface which is heated accordingly. This heat finds its way back into the atmosphere as a result of turbulent transport through the atmospheric boundary layer. Most of the solar energy absorbed by the ocean is used to evaporate water. Water vapor in the atmosphere acts as a reservoir for storage of heat that can be released later. As the air ascends, it cools. When it becomes saturated, water vapor condenses with consequent release of latent heat. Heating is dominated in the tropical atmosphere by release of latent heat. Separate bands of relatively deep heating are observed at mid-latitudes where active weather systems result in enhanced precipitation and release of latent heat.

The atmospheric system consists of dry air and water. Its total entropy $S^{\text {total }}$ and total static energy $E^{\text {total }}$, according to thermodynamics, can be expressed as: $S^{\text {total }}=S^{d r y}+S^{H_{2} O}$ and $E^{\text {total }}=E^{d r y}+E^{H_{2} O}$, where $S^{\text {dry }}$ and $E^{\text {dry }}$ represent the associated entropy and static energy of the dry air component and $S^{\mathrm{H}_{2} \mathrm{O}}$ and $E^{\mathrm{H}_{2} \mathrm{O}}$ represent the associated entropy and static energy of the water component. The focus in this study is on how atmospheric motion of the dry air is maintained by diabatic heating. Condensation and evaporation of water are treated accordingly as external to the dry air component [32], namely as an exchange of entropy and energy with the 
dry air.

199 Regions of diabatic cooling, dominated by long wave radiation to space, occupy much of the 200 middle and upper troposphere. The rate of change of entropy, s, per unit mass is given by $201 \frac{d s}{d t}=Q / T$. The spatial distribution of entropy generation is similar to the spatial pattern of $Q$, as 202 illustrated in Fig. 9.

203 Diabatic heating includes contributions from radiative heating and cooling, release of latent 204 heat associated with phase transitions, heating by conduction of sensible heat, and heating 205 by frictional dissipation:

$$
Q=-\frac{1}{\rho}\left\{\nabla \cdot F_{\text {rad }}+\rho L(e-c)+\nabla \cdot J_{H}+\tau: \nabla \vec{v}\right\}
$$

207 where $\rho$ is the density of air, $L$ is the latent heat of condensation, $c$ and $e$ are the rates of 208 condensation and evaporation per unit mass, $F_{\text {rad }}$ is the net radiative flux, $J_{H}$ is the sensible 209 heat flux due to conduction, $\tau$ is the wind tress tensor, and $\vec{v}$ is the wind velocity.

210 The diabatic heating term $Q$ can be written as $Q=Q_{h}+Q_{f}$, where $Q_{h}$ accounts for 211 radiative heating (solar and infrared), latent heating and heating due to conduction:

$$
Q_{h}=-\frac{1}{\rho}\left\{\nabla \cdot F_{r a d}+\rho L(e-c)+\nabla \cdot J_{H}\right\}
$$

213 The second component, $Q_{f}$, is associated with frictional dissipation:

$$
Q_{f}=-\frac{1}{\rho} \cdot \tau: \nabla \vec{v}
$$

215

216

By separating $Q_{h}$ from $Q$, we may consider $Q_{h}$ as the external heating responsible, from a thermodynamic perspective, for the motion of the dry air. In the long run, the globally integrated values for $Q_{f}$ must be balanced by global production of kinetic energy, equal therefore to $2.46 \mathrm{~W} / \mathrm{m}^{2}$. Consequently, we may rewrite the generation of entropy as: 
220 where $\frac{d s_{h}}{d t}=Q_{h} / T, \frac{d s_{f}}{d t}=Q_{f} / T$ and $T$ is the temperature of the environment in the region

221 where heat is either absorbed or released [33, 34].

222 In the long run, the entropy $S$ of the entire atmosphere must remain constant. Thus, with 223 the long term mean indicated by " "

$$
\int_{\text {global }} \overline{\rho \frac{d s_{h}}{d t}} d V+\int_{\text {global }} \overline{\rho \frac{d s_{f}}{d t}} d V=0
$$

225 or

$$
\int_{\text {global }} \overline{\rho \frac{Q_{h}}{T}} d V+\int_{\text {global }} \overline{\rho \frac{Q_{f}}{T}} d V=0
$$

227 Since $Q_{f}$ and $T$ are always positive, the second term $\int_{\text {global }} \overline{\rho \frac{Q_{f}}{T}} d V$ representing the entropy 228 generation associated with dissipation is greater than zero, which implies that $229 \int_{\text {global }} \rho\left(\frac{Q_{h}}{T}\right) d V<0$. It follows that the $Q_{h}$ and $T$ fields must be positively correlated. In 230 other words, the general circulation can be maintained against the disordering impact of 231 friction only if the heating occurs in warmer regions of the atmosphere with cooling in 232 colder regions. Fig. 10 summarizes the creation and dissipation of kinetic energy in the 233 atmosphere from a thermodynamic perspective.

234 The global heat source $Q_{i n}$ in Fig. 10 represents the heat that the atmosphere absorbs at the 235 higher temperature, $T_{\text {hot }}$, environment in order to do mechanical work. It is defined as $236 \int_{Q_{h}>0} \rho Q_{h} d V$. The global heat sink $Q_{\text {out }}$ in Fig. 10 represents the heat that the atmosphere 237 releases into the lower temperature, $T_{\text {cold }}$, environment and is defined by $Q_{\text {out }}=$ $238 \int_{Q_{h}<0} \rho Q_{h} d V$. 
239 The mechanical work produced by the atmosphere is dissipated by friction and converted to heat

240 that is released back into the atmosphere. This process is thermally equivalent to using the

241 mechanical work to turn on a heater and return the exhausted heat back to the atmosphere, as

242 depicted in Fig. 10. However, it is difficult to distinguish between $Q_{h}$ and $Q_{f}$, and the absolute

243 value of the global integral of $Q_{f}$ is negligible compared to the global integral for $Q_{\text {in }}$ and $Q_{\text {out }}$.

244 Thus, the global heat source $Q_{\text {in }}$ can be approximated as: $Q_{\text {in }} \approx \int_{Q>0} \rho Q d V$ with $Q_{\text {out }}$

245 approximated as: $Q_{\text {out }} \approx \int_{Q<0} \rho Q d V$.

246 The value for the global heat source $\int_{Q>0} \rho Q d V$ averaged over the past three decades is estimated

247 at $244 \mathrm{~W} / \mathrm{m}^{2}$. The average kinetic energy production rate over the same period is calculated as

$2482.46 \mathrm{~W} / \mathrm{m}^{2}$. It follows that the average efficiency for kinetic energy production is equal to

249 approximately $1 \%$.

250 The effective temperature $\left\langle T_{\text {hot }}\right\rangle$ at which heat is absorbed can be calculated as:

251

$$
\left\langle T_{h o t}\right\rangle=\frac{1}{\Delta S} \int_{t_{1}}^{t_{2}} \int_{Q_{h}>0} T \frac{d S}{d t} d V d t
$$

252 or approximated as:

$$
\left\langle T_{h o t}\right\rangle \approx \frac{1}{\Delta S} \int_{t_{1}}^{t_{2}} \int_{Q>0} T \frac{d S}{d t} d V d t
$$

254 where $\Delta S=\int_{t_{1}}^{t_{2}} \int_{Q_{h}>0} \frac{d S}{d t} d V d t$, with $t_{1}$ and $t_{2}$ representing the starting and ending times for the 255 integration. In the long run, the entropy $S$ of the entire atmosphere is required to remain 256 constant. Equation (10) can be recast as:

$$
\frac{Q_{\text {in }}}{\left\langle T_{\text {hot }}\right\rangle}-\frac{Q_{\text {out }}}{\left\langle T_{\text {cold }}\right\rangle}+\frac{C}{T_{\text {surface }}}=0
$$

258 where $\frac{C}{T_{\text {surface }}}$ represents the entropy generation due to dissipation [34]. The effective 
temperature $\left\langle T_{\text {cold }}\right\rangle$ at which heat is released can be estimated accordingly.

260 The schematic illustration of the dry air component of the atmosphere as a thermal engine is 261 summarized in Fig. 11, with values included here representing averages for the past 32 years. 262 The dry air component of the atmosphere acts as a thermal engine, absorbing heat at a 263 temperature of approximately $256 K$, releasing heat at a temperature of approximately $252 K$. 264 The process produces kinetic energy at a rate of $2.46 \mathrm{~W} / \mathrm{m}^{2}$ sustaining thus the circulation of the 265 atmosphere against friction.

\section{7. Discussion and summary}

267 The study started with a quantification of the total kinetic energy stock of the atmosphere and 268 subsequently investigated how kinetic energy is generated and dissipated from mechanical and 269 thermodynamic perspectives.

270 The total kinetic energy stock of the atmosphere displays significant inter-annual variability, as 271 indicated in Fig. 1 and Fig. 2, with the changing phases of the ENSO cycle playing an important 272 role. This inter-annual variation reflects the fact that the wind energy potential for a particular 273 location can fluctuate on a long-term basis, under the influences of long-term atmospheric 274 oscillations which can alter the circulation of the atmosphere including the distribution of kinetic 275 energy.

276 To illustrate the inter-annual variation of wind energy potentials, we select two locations, one in 277 Texas $\left(34.5^{\circ} \mathrm{N}, 101.3^{\circ} \mathrm{W}\right)$ and the other in North Dakota $\left(47^{\circ} \mathrm{N}, 101.3^{\circ} \mathrm{W}\right)$, as indicated in Fig 278 12a. In calculating the potential electricity generated from wind, we chose to use power curves 279 and technical parameters for the GE 2.5 MW turbines (rated wind speed $12.0 \mathrm{~m} / \mathrm{s}$, cut-in wind 280 speed $3.5 \mathrm{~m} / \mathrm{s}$, and cut-out speed $25.0 \mathrm{~m} / \mathrm{s}$ ). The power curve of the wind turbine defines the 
281 variation of power output as a function of wind speed. The hourly wind speeds at $100 \mathrm{~m}$ are

282 extrapolated from winds at $50 \mathrm{~m}$ according to the relation: $V_{100}=V_{50} \cdot \frac{\ln \left(Z_{100} / Z_{0}\right)}{\ln \left(Z_{50} / Z_{0}\right)}$, where $\mathrm{V}_{100}$

283 and $V_{50}$ indicate hourly values for the wind speed at $100 \mathrm{~m}$ and $50 \mathrm{~m}$ respectively, $\mathrm{Z}_{100}$ and $\mathrm{Z}_{50}$

284 define the elevation of the turbine hub $(100 \mathrm{~m})$ and the reference $50 \mathrm{~m}$ altitude, and $\mathrm{Z}_{0}$ defines

285 the surface roughness length.

286 The capacity factor (CF) values in Fig. 12b, at a particular time $t_{0}$, are calculated as:

$$
C F\left(t_{0}\right)=\left(\int_{t_{0}-0.5 \text { year }}^{t_{0}+0.5 \text { year }} P_{\text {real }}(t) \cdot d t\right) /\left(P_{\text {rated }} \cdot 1 \text { year }\right)
$$

where $P_{\text {real }}$ denotes the power actually realized, and $P_{\text {rated }}$ refers to the power that could have been realized had conditions permitted the turbine to operate at its name plate capacity. The 290 seasonality of wind energy potentials, represent by $\mathrm{CF}$ values, have been removed due to the averaging period defined in equation (15): averaging $P_{\text {real }}$ from $t_{0}-0.5$ year to $t_{0}+0.5$ year.

292 CF values of the wind farms in Texas and North Dakota display significant interanual variation. 293 The ups and downs of CF values in Fig 12b are the embodiments of the long-term atmospheric 294 oscillations. Modern wind turbines are designed to work with an anticipated lifespan of 20 years. 295 Wind energy potentials, as exemplified by the Texas and North Dakota cases, can vary on a year296 to-year basis with a large amplitude over a 20 years period. Predictions of wind power for the 297 next 20 years, or at least limits on its possible variation, will pose an important challenge for 298 prospective investors in wind power.

299 The kinetic energy of wind in the atmosphere is constantly dissipated by friction. The residence 300 time of kinetic energy, $\tau$, is estimated at 6.9 days. The dry air component of the atmosphere 301 generates kinetic energy as a thermal engine to sustain the general circulation of the atmosphere 
against frictional dissipation. Key thermodynamic properties were quantified, including the kinetic energy production rate, $C$, the heat absorption rate, $Q_{i n}$, the effective temperature at which heat is absorbed, $\left\langle T_{h o t}\right\rangle$, and the effective temperature at which heat is released, $\left\langle T_{\text {cold }}\right\rangle$.

The calculations of these key properties are based on the assimilated meteorological data from the MERRA compilation. Data assimilation is the process of incorporating historical observations of the atmosphere into a numerical physical model, and produces the most reliable estimate of the past meteorological conditions. However, some uncertainties with the final outputs, such as wind speed data, cannot be completely eliminated.

The kinetic energy production rate, $C$, is calculated from a mechanical perspective using wind speed data and pressure gradient data. Wind speed data and pressure data are accurately obtained in the assimilation process [24]. Thus, the kinetic energy production quantified here is reliable, and the results obtained are consistent with other studies [18-22]. The quantification of other variables, notably diabatic heating and effective temperatures, involves parameters such as the vertical velocity of the air with relatively large uncertainties [24]. Absolute values of these thermodynamic properties are subject to relatively large uncertainty, depending as they do on the accuracy of the input data, the MERRA analysis in the case. It is not possible to place error bars on the values derived here for these parameters.

The globally averaged combined land and ocean surface temperature data indicate a warming of $0.85 \mathrm{~K}$, over the period 1880 to 2012 [35]. A number of studies argued that the warming climate over the past decades has influenced the wind resource potential [36-44]. The upward trend in kinetic energy production rate obtained here confirms the fact that the thermodynamic conditions of the atmosphere have undergone a significant change over the past 32 years. A key question is 
whether the conclusions reached in the study may be conditioned by the use of a specific data base. Other datasets including NCEP-1, NCEP-2, ERA-40 and JRA-25 should be employed in future to compare with results from the present study. Regarding the future warming climate, according to the IPCC 2014 report [35], the change in global surface temperature by the end of the 21 st century is likely to exceed $1.5^{\circ} \mathrm{C}$ relative to the average from year 1850 to 1900 under most future greenhouse emission scenarios. It is essential to investigate how the atmosphere, as a thermal engine, will adjust under the different scenarios, altering thus the distributions and values of wind energy resources.

A number of studies have suggested that large scale deployment of wind farms could potentially influence the circulation of the atmosphere [9, 11-16, 45-49]. With a simple parameterization of turbine operations, Miller et al. [46] performed numerical experiments and found that a maximum of $34 T W$ of electricity could be generated. Marvel et al. [47] extended Miller's work by parameterizing the turbines as sinks for momentum and concluded that wind turbines placed at the Earth's surface could extract kinetic energy at a rate of at least $400 \mathrm{TW}$, whereas highaltitude wind turbines could extract more than 1,800 TW. With a different global model and parameterization approach, Jacobson and Archer [48] argued that as the number of wind turbines increases over large geographic regions, power extraction would first increase linearly, then converge to a saturation limit, with a saturation potential in excess of $250 \mathrm{TW}$ at $100 \mathrm{~m}$ globally, $380 \mathrm{TW}$ at $10 \mathrm{~km}$. There is a notable discrepancy between these various estimates. Adams and Keith [16] addressed the question using a mesoscale model. They concluded that wind power production would be limited to about $1 \mathrm{~W} / \mathrm{m}^{2}$ at wind farm scales larger than about $100 \mathrm{~km}^{2}$ and that the mesoscale model results are quantitatively consistent with results from global models that simulated the climate response to much larger wind power capacities. However, as noted 
347 earlier, the energetics of the entire atmosphere is different from the energetics of the mesoscale 348 region.

349 The quantity of wind energy that can be extracted from the atmosphere to generate electricity 350 depends ultimately on the rate at which kinetic energy is produced, not on the quantity of kinetic 351 energy stored in the atmosphere [50]. Answering the question of the ultimate limit of the 352 atmosphere as a source of wind-generated electric power requires a detailed study of the 353 underlying thermodynamics of the global atmosphere. While not trying to quantify the ultimate 354 wind potential, this study provides an analytical framework that can be adapted for future studies 355 addressing the ultimate wind energy potential and the potential perturbations to the atmospheric 356 circulation that could arise as a result of significant exploitation of this potential. It will be 357 critical to understand how the key thermodynamic variables, such as the effective temperature

$358\left(T_{\text {hot }}\right.$ and $\left.T_{\text {cold }}\right)$ and diabatic heating $\left(Q_{\text {in }}\right.$ and $\left.Q_{\text {out }}\right)$, evolve as increasing numbers of large scale 359 wind farms are deployed.

\section{Acknowledgements}

362 The work described here was supported by the National Science Foundation, NSF-AGS-1019134.

363 Junling Huang was also supported by the Harvard Graduate Consortium on Energy and 364 Environment. We acknowledge helpful and constructive comments from Michael J. Aziz, and Xi 365 Lu. 


\section{Reference:}

[1] The World Wind Energy Association 2013 report. April 2014, Bonn, Germany.

[2] Landberg L, Myllerup L, Rathmann O, Petersen EL, Jørgensen BH, Badger J, and Mortensen NG. Wind resource estimation—an overview. Wind Energy 2003; 6:3-261.

[3] Hoogwijk M, de Vries B, and Turkenburg W. Assessment of the global and regional geographical, technical and economic potential of onshore wind energy. Energy Economics 2004; 26:5-889.

[4] Archer CL, and Jacobson MZ. Evaluation of global wind power. Journal of Geophysical Research: Atmospheres (1984-2012) 2005; 110:D12.

[5] Lu X, McElroy MB, and Kiviluoma J. Global potential for wind-generated electricity. Proceedings of the National Academy of Sciences 2009; 106:27-10933.

[6] Tapiador FJ. Assessment of renewable energy potential through satellite data and numerical models. Energy \& Environmental Science 2009; 2:11-1142.

[7] de Castro C, Mediavilla M, Miguel LJ, and Frechoso F. Global wind power potential: Physical and technological limits. Energy Policy 2011; 39:10-6677.

[8] Zhou Y, Luckow P, Smith SJ, and Clarke L. Evaluation of global onshore wind energy potential and generation costs. Environmental science \& technology 2012; 46:14-7857.

[9] Keith DW, DeCarolis JF, Denkenberger DC, Lenschow DH, Malyshev SL, Pacala S, and Rasch PJ. The influence of large-scale wind power on global climate. Proceedings of the national academy of sciences of the United States of America 2004; 101:46-16115. 
389 [10] Wang C, Prinn RG. Potential climatic impacts and reliability of very large-scale wind farms. 390 Atmospheric Chemistry and Physics 2010; 10:4-2053.

391 [11] Wang C, Prinn RG. Potential climatic impacts and reliability of large-scale offshore wind 392 farms. Environmental Research Letters 2011; 6:2-025101.

393 [12] Walsh-Thomas JM, Cervone G, Agouris P, Manca G. Further evidence of impacts of large394 scale wind farms on land surface temperature. Renewable and Sustainable Energy Reviews, 2012; $395 \quad 16: 8-6432$.

396 [13] Fitch AC, Olson JB, Lundquist JK, Dudhia J, Gupta AK, Michalakes J, Barstad I. Local and 397 mesoscale impacts of wind farms as parameterized in a mesoscale NWP model. Monthly 398 Weather Review, 2012; 140:9-3017.

399 [14] Fitch AC, Lundquist JK, Olson JB. Mesoscale influences of wind farms throughout a 400 diurnal cycle. Monthly Weather Review 2013; 141:7-2173.

401 [15] Fitch AC, Olson JB, Lundquist JK. Parameterization of wind farms in climate models. 402 Journal of Climate 2013; 26:17-6439.

403 [16] Adams AS, Keith DW. Are global wind power resource estimates overstated? 404 Environmental Research Letters 2013; 8:1-015021.

405 [17] Lorenz EN. Available potential energy and the maintenance of the general circulation. 406 Tellus 1955; 7:2-157.

407 [18] Oort AH. On estimates of the atmospheric energy cycle. Monthly Weather Review 1964; $408 \quad 92: 11-483$. 
409 [19] Oort AH, Yienger JJ. Observed interannual variability in the Hadley circulation and its 410 connection to ENSO. Journal of Climate 1996; 9:11-2751.

411 [20] Li L, Ingersoll AP, Jiang X, Feldman D, Yung YL. Lorenz energy cycle of the global 412 atmosphere based on reanalysis datasets. Geophysical Research Letters 2007; 34:16.

413 [21] Marques CAF, Rocha A, Corte-Real J. Comparative energetics of ERA-40, JRA-25 and 414 NCEP-R2 reanalysis, in the wave number domain. Dynamics of Atmospheres and Oceans 2010; $415 \quad 50: 3-375$.

416 [22] Kim YH, Kim MK. Examination of the global lorenz energy cycle using MERRA and 417 NCEP-reanalysis 2. Climate Dynamics 2013; 40:5-6.

418 [23] Lorenz EN. The nature and theory of the general circulation of the atmosphere (Vol. 218).

419 Geneva: World Meteorological Organization; 1967.

420 [24] Rienecker M, et al. The GEOS-5 data assimilation system-Documentation of versions 421 5.0.1 and 5.1.0. NASA GSFC, Tech. Rep. Series on Global Modeling and Data Assimilation 422 2007; NASA/TM-2007-104606, Vol. 27.

423 [25] Huang J, Lu X, McElroy MB. Meteorologically defined limits to reduction in the variability 424 of outputs from a coupled wind farm system in the Central US. Renewable Energy 2014; 62: $425 \quad 331-340$.

426 [26] Heide D, Von Bremen L, Greiner M., Hoffmann C, Speckmann M, Bofinger S. Seasonal 427 optimal mix of wind and solar power in a future, highly renewable Europe. Renewable Energy $4282010 ; 35: 11-2483$. 
429 [27] Archer CL, and Jacobson MZ. Geographical and seasonal variability of the global "practical" 430 wind resources. Applied Geography 2013; 45: 119.

431 [28] Kung EC. Large-scale balance of kinetic energy in the atmosphere. Mon. Wea. Rev 1966; $432 \quad 94: 11-627$.

433 [29] Holton JR, and Hakim GJ. An introduction to dynamic meteorology. Academic press; 2013.

434 [30] Hagos S, et al. Estimates of tropical diabatic heating profiles: Commonalities and 435 uncertainties. Journal of Climate 2010; 23:3-542.

436 [31] Ling J, Zhang C. Diabatic heating profiles in recent global reanalyses. Journal of Climate $437 \quad 2013 ; 26: 10-3307$.

438 [32] Johnson DR. "General Coldness of Climate Models" and the Second Law: Implications for 439 Modeling the Earth System. Journal of climate 1997; 10:11-2826.

440 [33] Peixoto JP, Oort AH, De Almeida M, Tomé A. Entropy budget of the atmosphere. Journal 441 of Geophysical Research: Atmospheres (1984-2012) 1991; 96:D6-10981.

442 [34] Peixoto JP, Oort AH. Physics of climate. American institute of physics; 1992.

443 [35] Stocker TF, et al. Climate Change 2013. The Physical Science Basis. Working Group I 444 Contribution to the Fifth Assessment Report of the Intergovernmental Panel on Climate Change445 Abstract for decision-makers. Groupe d'experts intergouvernemental sur l'evolution du 446 climat/Intergovernmental Panel on Climate Change-IPCC, C/O World Meteorological 447 Organization, 7bis Avenue de la Paix, CP 2300 CH-1211 Geneva 2 (Switzerland), 2013.

448 [36] Breslow PB, Sailor DJ. Vulnerability of wind power resources to climate change in the 
449 continental United States. Renewable Energy 2002; 27:4-585.

450 [37] Pryor SC, Schoof JT, Barthelmie RJ. Climate change impacts on wind speeds and wind 451 energy density in northern Europe: empirical downscaling of multiple AOGCMs. Climate Res. $452 \quad 2005 ; 29: 183$.

453 [38] Sailor DJ, Smith M, Hart M. Climate change implications for wind power resources in the 454 Northwest United States. Renewable Energy 2008; 33:11-2393.

455 [39] Bloom A, Kotroni V, Lagouvardos K. Climate change impact of wind energy availability in 456 the Eastern Mediterranean using the regional climate model PRECIS. Natural Hazards and Earth $457 \quad$ System Science 2008; 8:6-1249.

458 [40] Pryor SC, Barthelmie RJ. Climate change impacts on wind energy: A review. Renewable 459 and sustainable energy reviews 2010; 14:1-430.

460 [41] Mideksa TK, Kallbekken S. The impact of climate change on the electricity market: A 461 review. Energy Policy 2010; 38:7-3579.

462 [42] Pereira de Lucena, AF, Szklo AS, Schaeffer R., Dutra RM. The vulnerability of wind power 463 to climate change in Brazil. Renewable Energy 2010; 35:5-904.

464 [43] Wan H, Wang XL, and Swail VR. Homogenization and trend analysis of Canadian near465 surface wind speeds. Journal of Climate 2010; 23:5-1209.

466 [44] Jiang Y, Luo Y, Zhao Z, Tao S. Changes in wind speed over China during 1956-2004.

467 Theoretical and Applied Climatology 2010; 99:3-4. 
468 [45] Lu H, Porté-Agel F. Large-eddy simulation of a very large wind farm in a stable

469 atmospheric boundary layer. Physics of Fluids (1994-present) 2011; 23:6-065101.

470 [46] Miller LM, Gans F, Kleidon A. Estimating maximum global land surface wind power

471 extractability and associated climatic consequences. Earth Syst. Dynam 2011; 2:1-1.

472 [47] Marvel K, Kravitz B, Caldeira K. Geophysical limits to global wind power. Nature Climate

473 Change 2013; 3:2-118.

474 [48] Jacobson MZ, Archer CL. Saturation wind power potential and its implications for wind

475 energy. Proceedings of the National Academy of Sciences 2012; 109:39-15679.

476 [49] Roy SB, Traiteur JJ. Impacts of wind farms on surface air temperatures. Proceedings of the

477 National Academy of Sciences 2010; 107:42-17899.

478 [50] Gustavson MR. Limits to wind power utilization. Science 1979; 204:4388-13.

479

480

481

482

483

484

485 


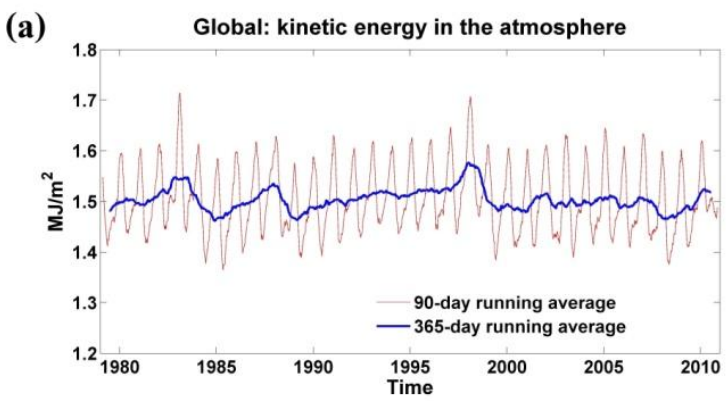

(b) Northern hemisphere: kinetic energy of the atmosphere

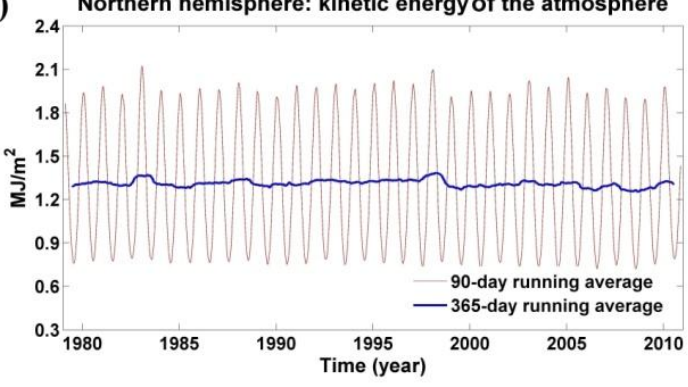

(c)

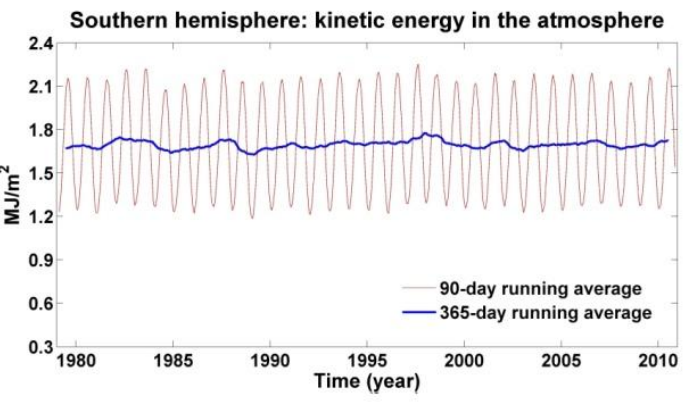

(d)

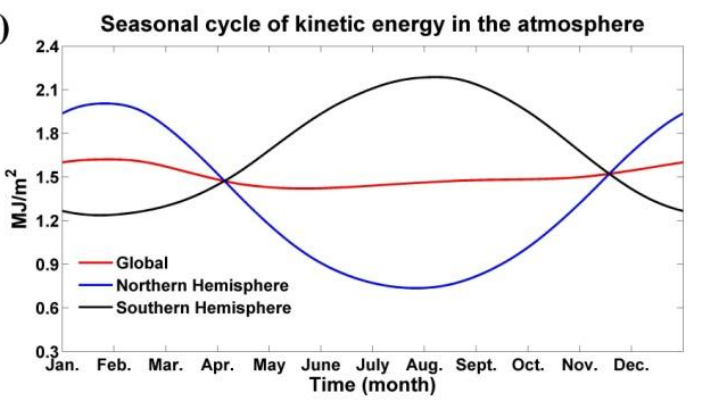

488 Fig. 1. (a) Variation of the global kinetic energy from January 1979 to December 2010. (b) 489 Variation of the Northern Hemisphere kinetic energy from January 1979 to December 2010. (c) 490 Variation of the Southern Hemisphere kinetic energy from January 1979 to December 2010. (d) 491 The composite seasonal cycle of the kinetic energy of the atmosphere averaged over the past 32 492 years. 

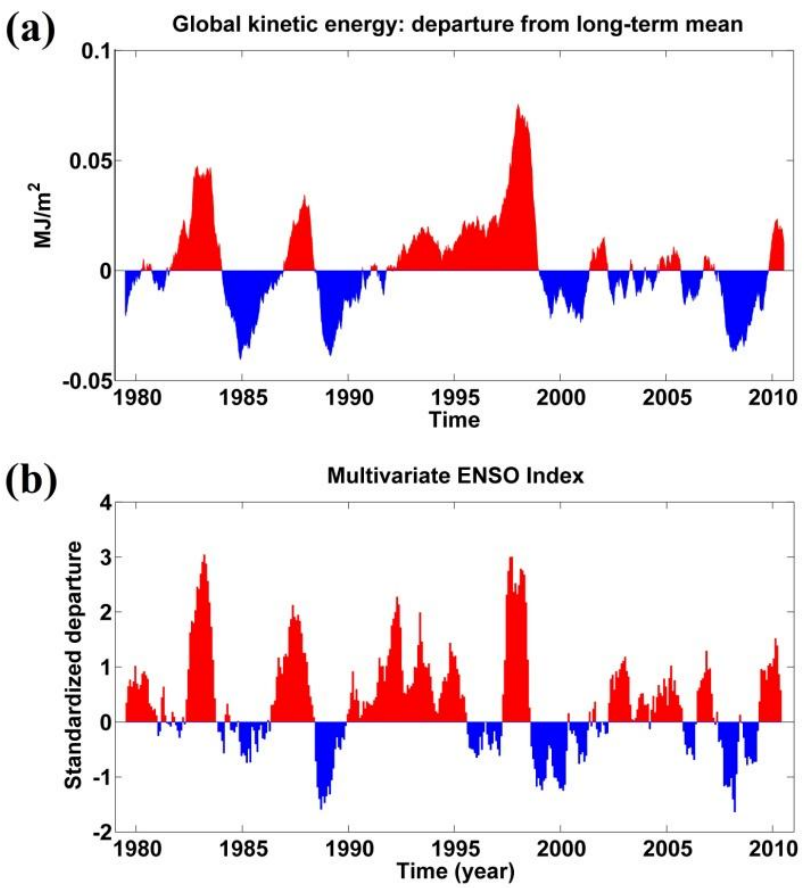

496

497 Fig. 2. (a) The departure of global kinetic energy from its 32 years' mean value $1.50 \mathrm{MJ} / \mathrm{m}^{2}$. The 498 seasonality of the departure is removed via 365-day running average. (b) The time series of the 499 500 501 502 503 504 

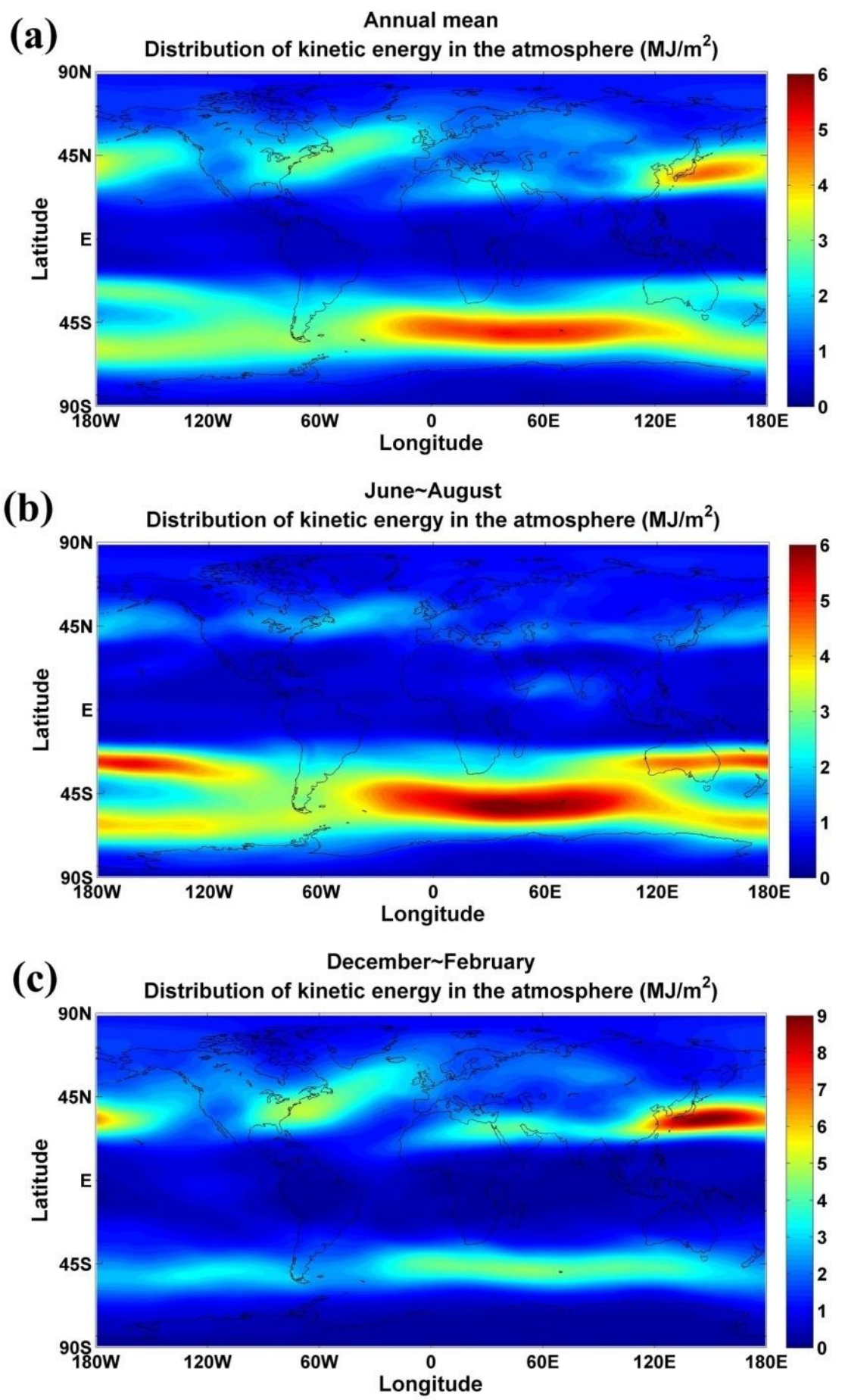

506 Fig. 3. (a) Spatial distribution of the annual mean kinetic energy of the atmosphere in $M J / m^{2}$, 507 calculated based the past 32 years' data. (b) June August, calculated based the past 32 years' 508 data. (c) December February, based on the past 32 years' data. 


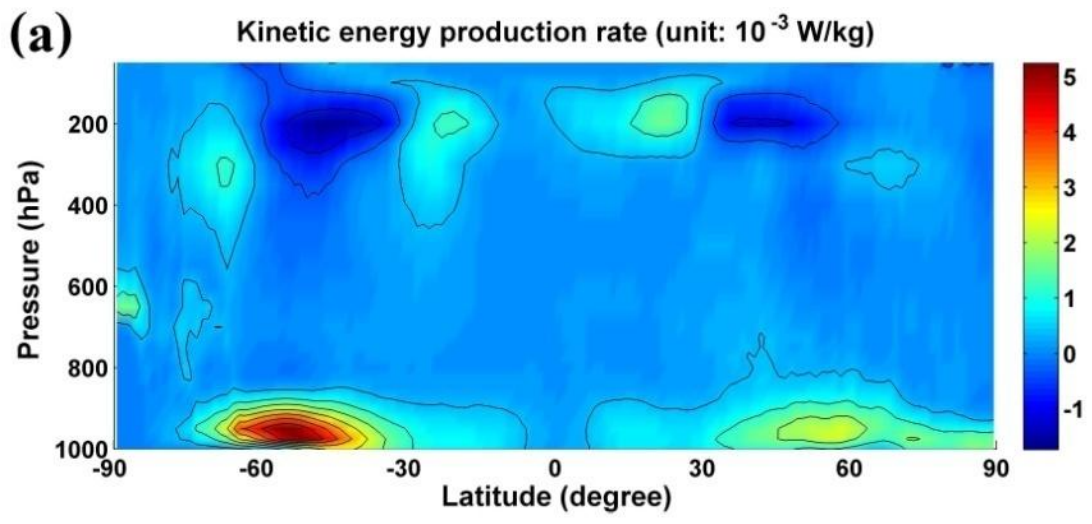

(b) OhPa 600hPa: Kinetic energy production rate (unit:w/ $/ \mathrm{m}^{2}$ )

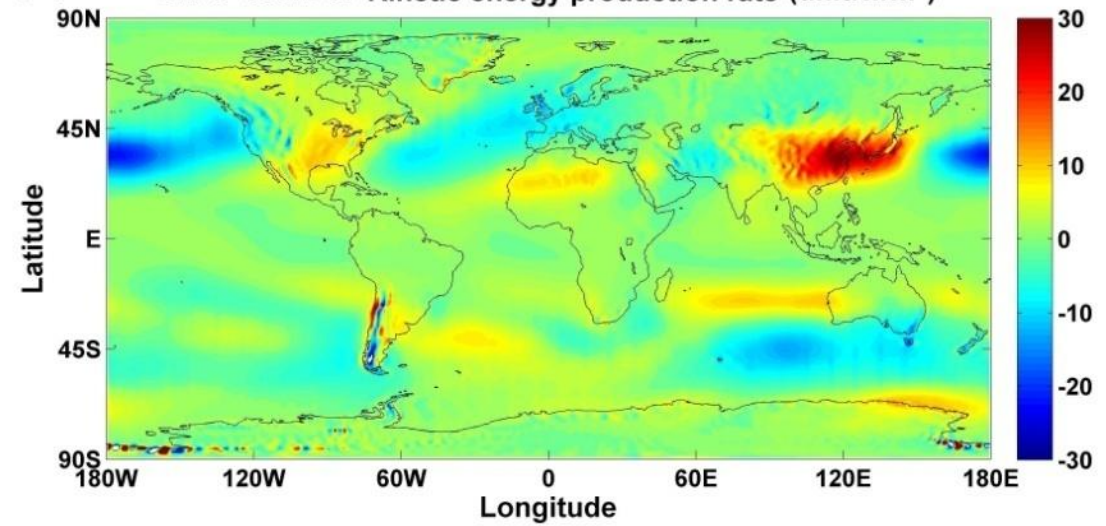

(c) $600 \mathrm{hPa} 1000 \mathrm{hPa}$ : Kinetic energy production rate (unit:w/m²)

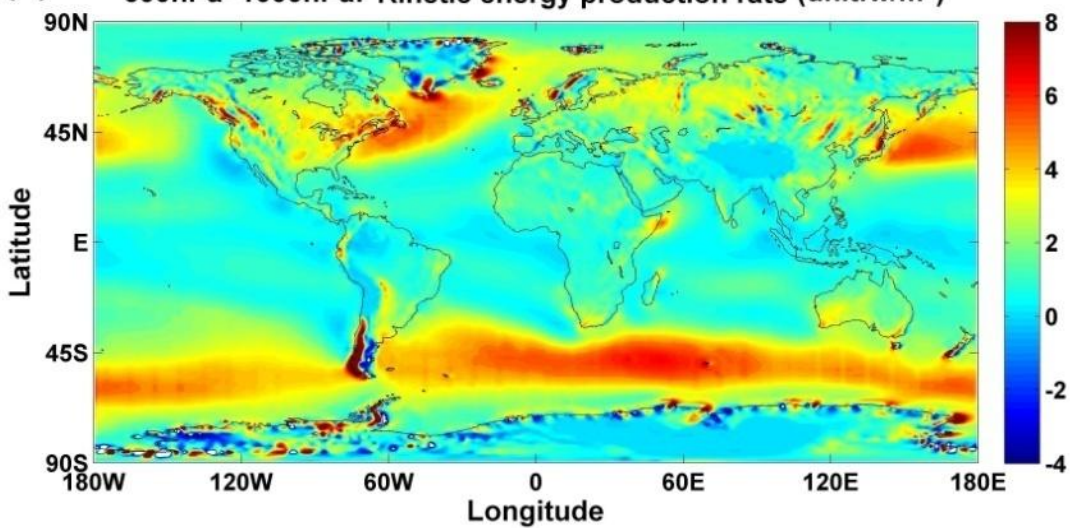

511 Fig. 4. (a) The vertical profile of kinetic energy production rate, $C$. (b) Kinetic energy production

512 rate, $C$, in the layer between $0 \mathrm{hPa} \sim 600 \mathrm{hPa}$. (c) Kinetic energy production rate, $C$, in the 513 layer between $600 \mathrm{hPa} \sim 1000 \mathrm{hPa}$. 

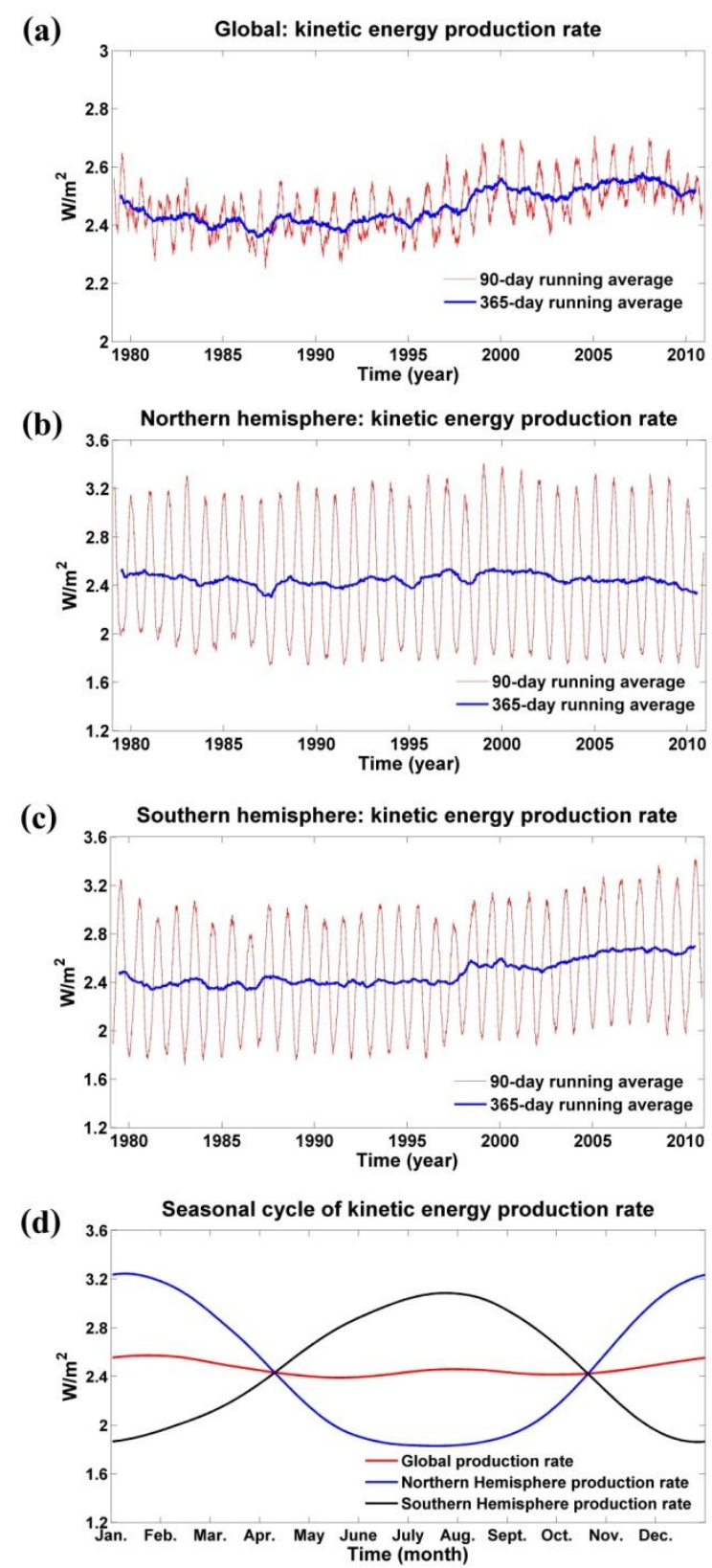

517 Fig. 5. (a) Variation of the global kinetic energy production rate, $C$, from January 1979 to 518 December 2010. (b) Variation of the Northern Hemisphere kinetic energy production trend, $C$, 519 from January 1979 to December 2010. (c) Variation of the Southern Hemisphere kinetic energy 520 production trend, $C$, from January 1979 to December 2010. (d) The composite seasonal cycle of 521 the kinetic energy production rate, $C$, based on the past 32 years' data. 

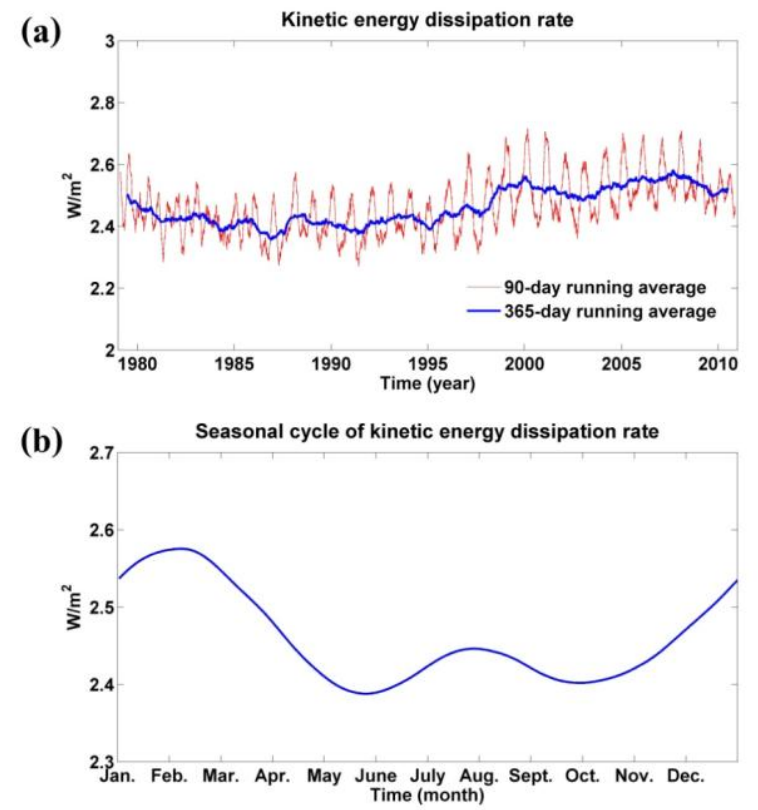

525 Fig. 6. (a) Variation of kinetic energy dissipation rate, $D$, from January 1979 to December 2010;

526 (b) The composite seasonal cycle based on the past 32 years.

527

528

529

530

531

532

533

534

535

536

537

538 


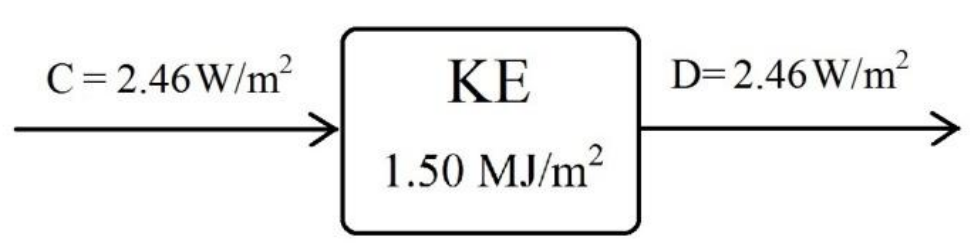

539

540 Fig. 7. Mechanical perspective on the budget of atmospheric kinetic energy.

541

542

543

544

545

546

547

548

549

550 

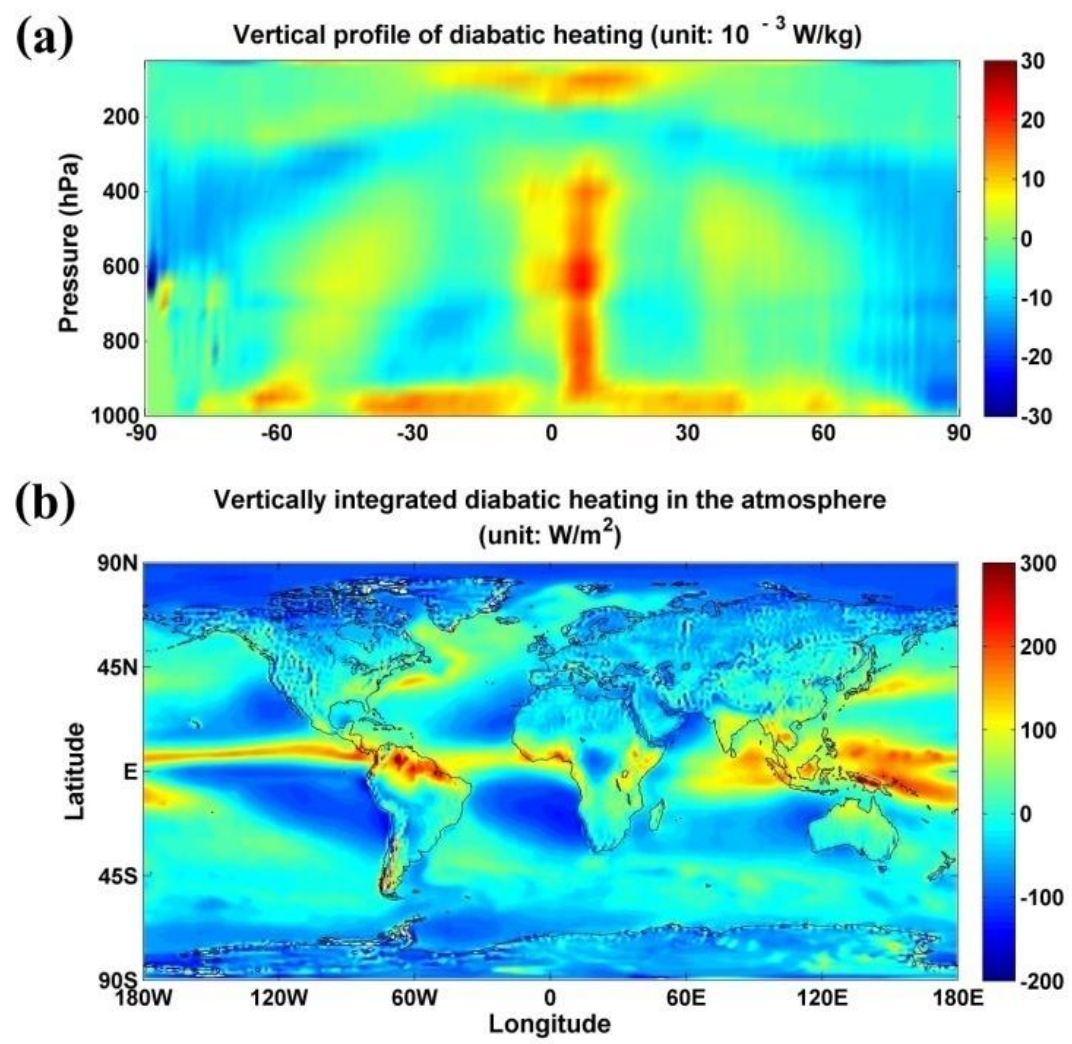

552 Fig. 8. (a) Vertical profile of diabatic heating. (b) Vertically integrated results. 
(a)

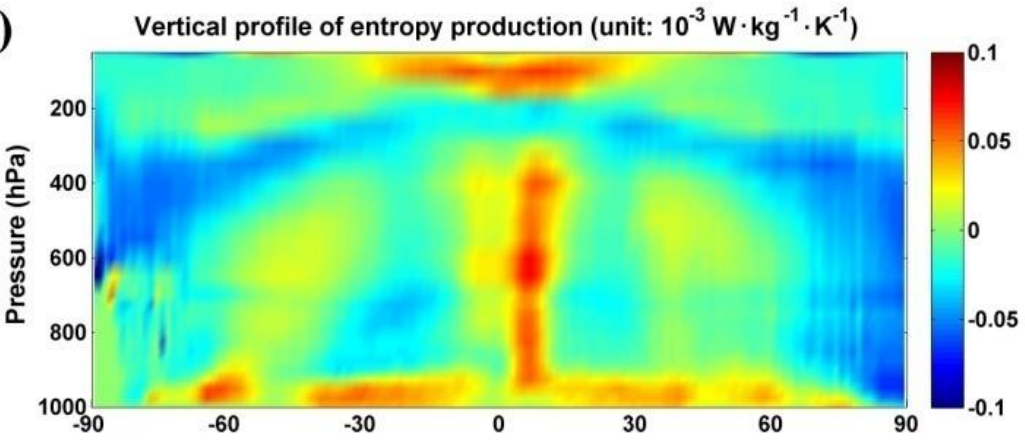

(b)

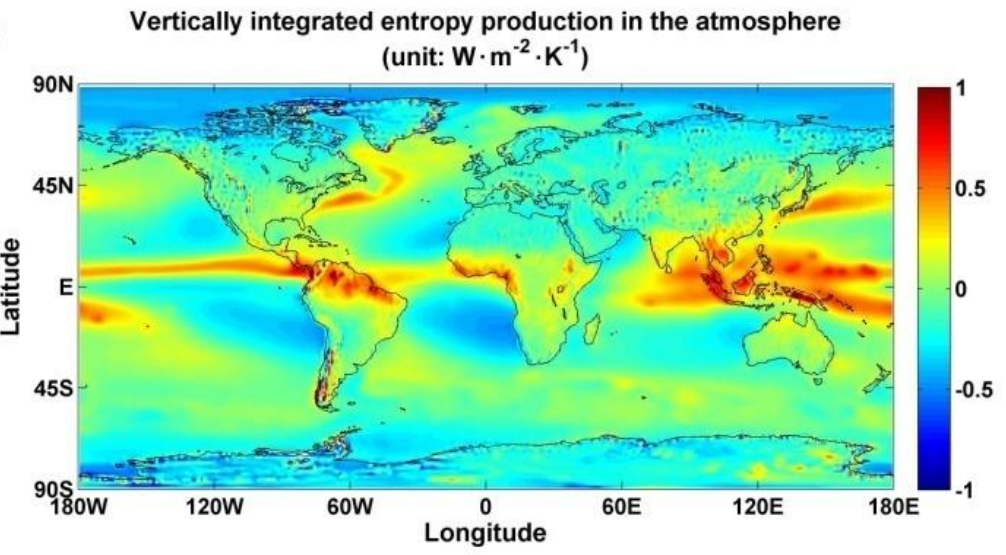

561

562

Fig. 9. (a) Vertical profile of entropy production. (b) Vertically integrated results. 


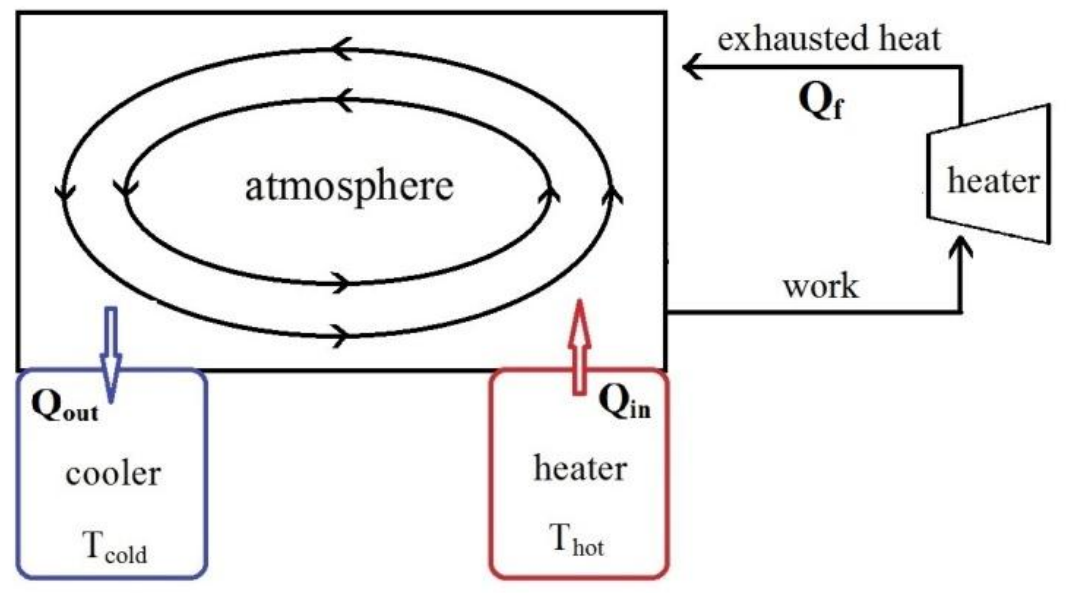

571

572 Fig. 10. Schematic depiction of the atmosphere as a thermal engine.

573

574

575

576

577

578

579

580

581

582

583

584

585

586

587 


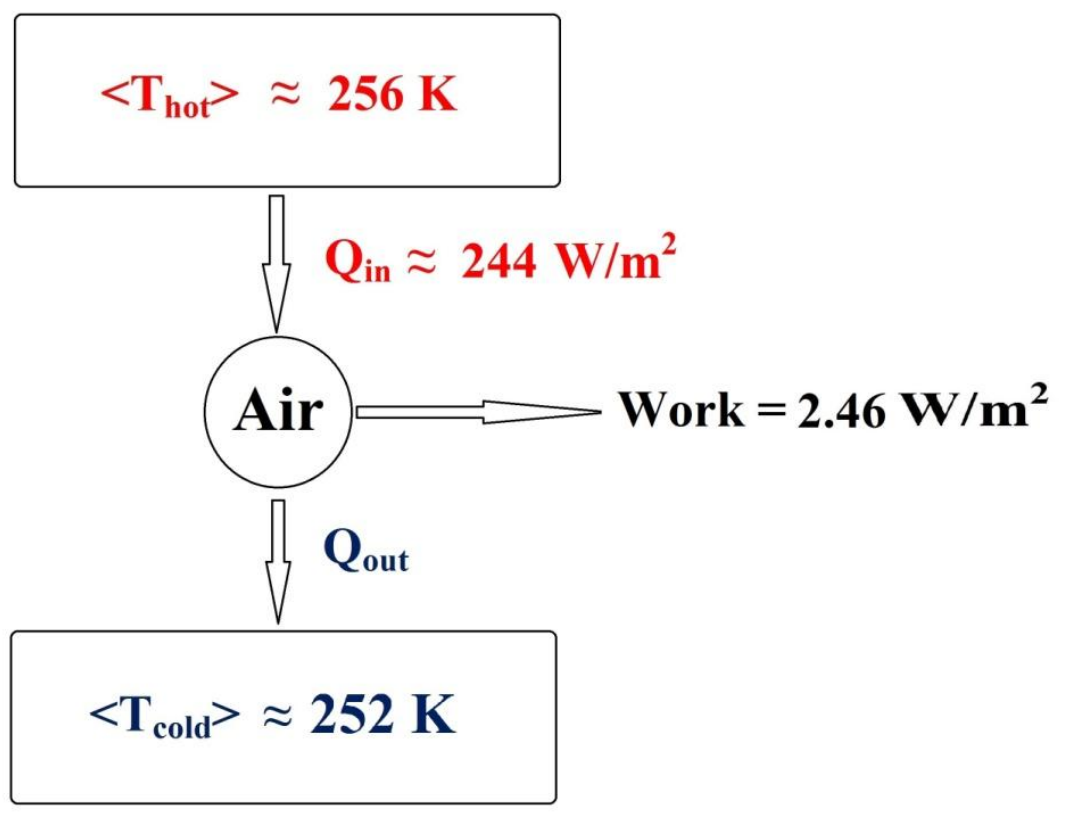

588

589 Fig. 11. Illustration of the atmosphere as a Carnot engine. Work, $C$, is dissipated ultimately by 590 friction.

591

592

593

594

595

596

597

598

599 
(a)

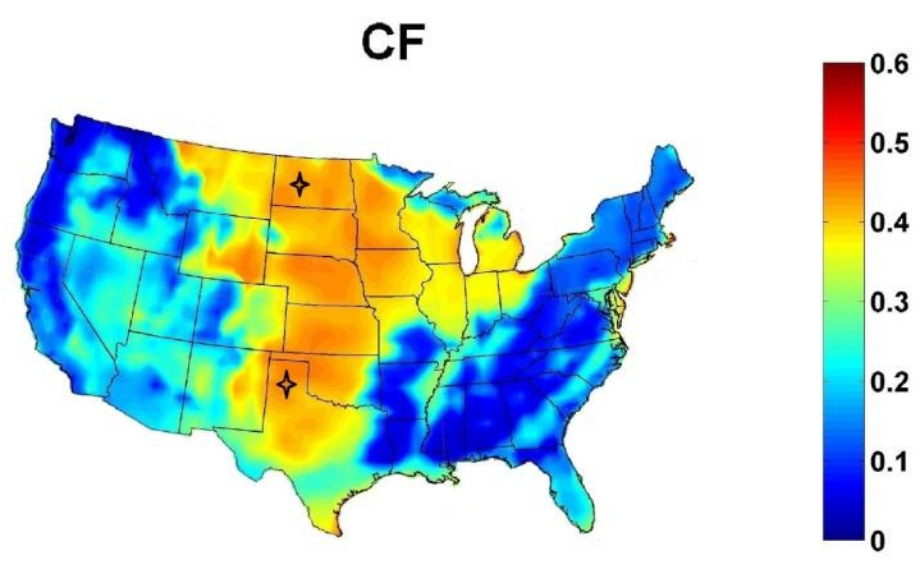

(b)

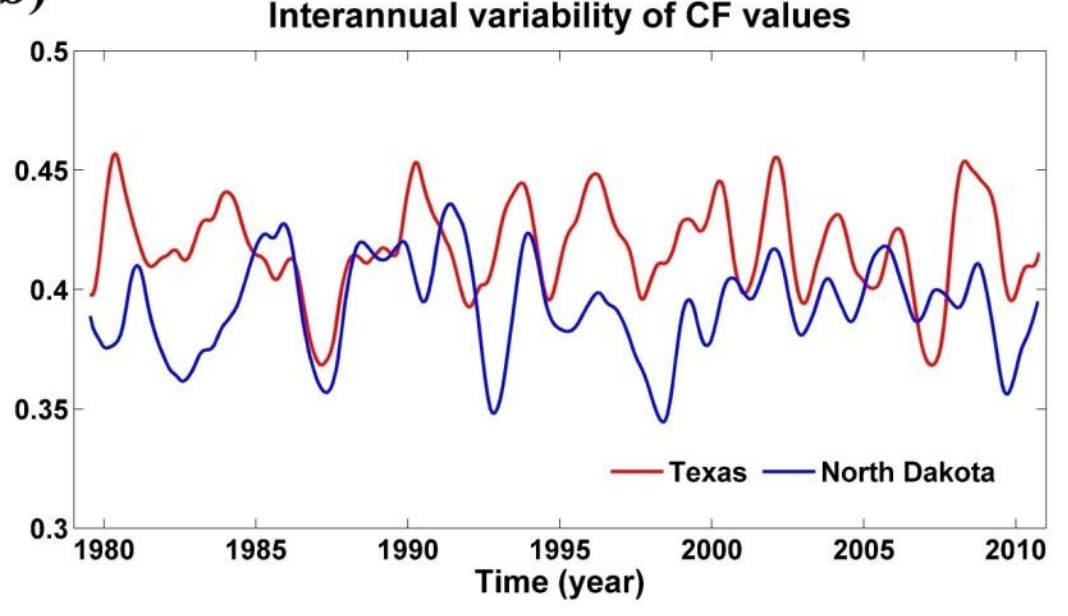

601 Fig. 12. (a) Color coded values for $\mathrm{CF}$ as a function of position averaged over the 32 year period 602 Jan 1st 1979 to Dec 30th 2013. Positions of two wind farms considered in this paper are 603 indicated by the stars. (b) CF values for two wind farms in Texas and North Dakota with 604 seasonal cycle removed. 